\title{
PEMBELAJARAN BIOLA DENGAN METODE SUZUKI PADA ANAK USIA DINI
}

\author{
Bagas Eka \\ Moh. Muttaqin \\ Universitas Negeri Semarang, Kampus Sekaran Gunungpati, Semarang, \\ E-mail: Bagaseka410@gmail.com
}

\begin{abstract}
Abstrak
All Mozart Music School adalah lembaga pendidikan non formal yang bergerak dibidang musik yang didirikan pada tahun 2011. Lembaga musik All Mozart Music School adalah tempat belajar musik bagi anak usia dini untuk mengembangkan talenta bermusik di Kota Kudus. Dalam penelitian ini masalah yang dikaji adalah "Bagaimanakah proses pembelajaran biola dengan metode Suzuki di All Mozart Music School"dan tujuan penelitiannya adalah untuk mengetahui proses pembelajaran biola dengan metode Suzuki di All Mozart Music School.

Penelitian ini menggunakan metode penelitian kualitatif, sedangkan teknik penyajiannya dalam bentuk deskriptif kualitatif. Data yang digunakan adalah seluruh data yang diperlukan dari All Mozart Music School, sedangkan teknik pengumpulan datanya: Observasi, wawancara dan studi dokumen. Instrumen pengumpulan data pada penelitian ini menggunakan observasi partisipatif, wawancara langsung, dan studi dokumen.

Hasil penelitian menunjukkan Pembelajaran biola di All Mozart Music School dilakukan secara privat dengan durasi 45 menit. Pembelajaran biola di All Mozart Music School menggunakan buku Suzuki sebagai bahan utama pembelajaran. Tahap materi yang diajarkan menurut isi yang ada dalam buku tersebut adalah (1) Guru memberikan pengarahan kepada murid tentang posisi berdiri. (2) Guru memberi pengarahan tentang cara memegang Bow yang disertai gambar tentang cara memegang bow yang baik dan benar. (3) Guru mulai memberikan pengarahan pada murid tentang tata cara mulai memegang senar biola. Tahap tersebut diikuti dengan mengenalkan materi lagu Lighty Row, yang merupakan contoh materi yang ada pada buku Suzuki. Pada lagu Lighty Row terdapat beberapa variasi ritmis sebagai awal pengenalan ritmis untuk memudahkan anak belajar biola. Kegiatan awal pembelajaran biola dengan Metode Suzuki dibagi menjadi 2 antara murid baru dan murid lama. Pada murid baru adalah mendengarkan pertanyaan guru seputar belajar biola, sedangkan untuk murid lama adalah menanyakan tugas pada pertemuan sebelumnya. Kegiatan inti pada murid baru adalah mendengarkan penjelasan guru dan memperoleh pengenalan biola dengan metode ceramah. Kegiatan inti pada murid lama adalah mendengarkan lagu dan menyimak demonstrasi. Murid menyimak dan menirukan contoh dari guru. Kegiatan akhir Metode Suzuki pada pembelajaran Biola di All Mozart Music School pada murid baru adalah mendengarkan pengulasan materi guru, sedangkan guru member motivasi dan mengucap salam. Murid lama mengalami refleksi dari pembelajaran biola yang telah dilakukan berupa kesalahan dan pembenaran proses pembelajaran. Guru melakukan laporan pembelajaran berupa catatan yang disampaikan kepada orang tua tentang perkembangan belajar anak.

Saran: (1) Bagi pengajar, pengajar biola di All Mozart Music School perlu memperbaiki cara penyampaian materi supaya lebih jelas dan dimengerti oleh muridnya. (2) Bagi All Mozart Music School, metode pembelajaran biola lebih difokuskan kepada masingmasing murid dengan bakat yang berbeda dapat lebih mudah untuk mengikuti materi-materi yang disampaikan.
\end{abstract}

Kata Kunci: Pembelajaran, Biola, Metode Suzuki, Anak Usia Dini 


\title{
LEARNING THE VIOLIN WITH THE SUZUKI IN EARLY CHILDHOOD THE ALL MOZART MUSIC SCHOOL IN THE KUDUS CITY
}

\begin{abstract}
Abstrack
All Mozart Music School institutions are non formal education moving in music founded in 2011.The music All Mozart Music School is where studied music for early childhood to develop talent bermusik in the Kudus city.In this research problems examined is how learning violin with the suzuki the All Mozart Music School research and purpose is to find learning violin with the suzuki the all mozart music school.This research in a qualitative study, while presented technique in the form of descriptive qualitative.The data used was all data required of All Mozart Music School, while technique: turnaround observation, interviews and study documents.An instrument data collection in this research using participatory observation, live interview, and study documents.

The research results show violin lessons in All Mozart Music School done in private with duration of 45 minutes. Violin lessons in All Mozart Music School using book suzuki as the principal ingredient of learning. Material stage taught according to the contents of which exists in the book is 1 Of teachers provide directives to students about a standing position. 2 The teachers giving instructions about the manner of holding bow that accompanied a picture about the manner of holding bow good and right. 3 The teachers started giving directives on the pupil on procedures started holds the strings up the violin. Followed the stage with the introduction of material lighty row song, that is an instance existing material on the books of suzuki.At song lighty row there are several variations of rhythmical as the introduction of rhythmical early to ease child learn the violin.

Inception work with the learning violin suzuki divided into 2 of the new and old students.To the new is hearing the questions about a violin lesson teachers, while for the long been asked duty in the past. Core activities to the new is listening explanation teachers and obtain the introduction of the violin with the talks. Core activities to the long been listening song and listened to demonstrations. Students and mimicked review example of teachers. The method at the end of suzuki learning violin the All Mozart Music School in new students are listening pengulasan matter teachers, while teachers member motivation and gave peace. Students long experience reflection of learning violin carried out of mistakes and justification learning. Teachers are doing learning of report notes from parents of progress learning a.

Advice: (1) For teachers, teachers violin the all mozart music school need to correct way this matter just to be clear and understandable by students. (2) For all mozart music school, the violin learning more focused on students with different talent can be easier to follow exercise delivered.
\end{abstract}

Keyword: Learning, Violin, Suzuki Method, Childhood

\section{PENDAHULUAN}

All Mozart Music School adalah sekolah musik yang memiliki kelas pembelajaran biola untuk anak usia dini. Kelas pembelajaran instrumen Biola di All Mozart Music School Kudus merupakan pilihan kelas yang cukup banyak diminati, dimana alat musik biola adalah alat musik yang menjadi pilihan anak-anak di kota Kudus. Metode yang digunakan dalam pembelajaran biola adalah metode Suzuki. Metode Suzuki adalah metode mengajar yang khusus menuntun anak-anak usia dini untuk bermain alat musik. 
Menurut Darsono (2000: 15), belajar dibagi menjadi empat aliran psikologis yaitu: Belajar menurut aliran Behavioristik, Belajar menurut aliran Humanistik, Belajar menurut aliran Gestalt dan Belajar menurut aliran Kognitif. Aliran belajar tersebut mempunyai ciri tersendiri dalam memahami setiap peristiwa pembelajaran. Kegiatan belajar yang efektif harus memiliki pengajar yang baik dalam menguasai proses belajar. Pengajar dituntut untuk mampu mengkoordinasi proses belajar, juga dituntut berusaha untuk melakukan kegiatan dalam mengkoordinasi proses belajar yang disebut pembelajaran. Proses belajar atau pembelajaran tidak sebatas pengajaran, diartikan guru dan murid mengalami proses belajar. Hal ini diperkuat kutipan Sardiman (1986: 48), bahwa mengajar pada dasarnya adalah usaha untuk menciptakan kondisi atau sistem lingkungan yang mendukung dan memungkinkan untuk berlangsungnya proses belajar.

Pada dasarnya pembelajaran adalah proses yang diselenggarakan oleh guru untuk membelajarkan murid dalam belajar, bagaimana belajar memperoleh dan memproses pengetahuan, ketrampilan dan sikap (Mudjiono 1994: 2). Menurut Sagala (2005: 61) pembelajaran adalah membelajarkan murid menggunakan asas pendidikan maupun teori belajar dimana merupakan penentu utama keberhasilan pendidikan. Dari beberapa pendapat di atas dapat disimpulkan bahwa pembelajaran yaitu proses belajar mengajar yang dilakukan pendidik (guru) dan peserta didik (murid) secara bersama-sama secara aktif guna mencapai tujuan dan pengembangan diri masing-masing.

Makna pembelajaran yang telah dijelaskan diperoleh informasi juga bahwa di dalam pembelajaran terdapat pula metode yang digunakan dalam pembelajaran. Metode dalam pembelajaran berisi tentang seluruh langkah disertai urutan kegiatan pembelajaran (Mukmin 2004: 61). Metode tersebut terdiri dari: (1) Metode Ceramah, (2) Metode Demonstrasi,
(3) Metode Latihan dan (4) Metode Pemberian Tugas. Metode yang telah dilakukan, harus terdapat evaluasi sebagai langkah untuk mengetahui seberapa jauh melaksanakan proses belajar mengajar. (TIM MKDK IKIP Semarang 1996: 63), evaluasi belajar menunjukkan suatu kegiatan untuk menentukan nilai pencapaian hasil belajar dengan mengetahui hasil pencapaian hasil belajar murid.

Biola (violin) merupakan nama umum dari keluarga alat musik gesek pada abad ke-17, seperti biola alto, cello, atau kontra bas (Syafiq 2003:315). Menurut Banoe (2003: 432) violin atau biola adalah alat gesek yang mempunyai suara tinggi dalam keluarga violine, ditala dalam g-d-ae, dimulai dalam nada g kecil. Definisi tersebut disimpulkan bahwa biola (violin) adalah alat musik dawai yang cara membunyikannya dengan cara digesek dengan alat penggesek yang disebut bow. Biola mempunyai empat senar (G-D-A-E) yang masing-masing senar di stem berbeda antara satu dengan lainnya dan menggunakan interval sempurna kelima (kwint). Biola menghasilkan suara yang nyaring dan mempunyai wilayah nada teringgi di antara keluarga instrumen gesek (biola alto, cello, double bass). Dalam penulisannya di notasi balok, biola menggunakan kunci $\mathrm{G}$.

Menurut bagiannya biola dibagi dalam empat bagian, (Mathews \& Thompson 2011: 52) yaitu: badan biola, leher biola, jembatan biola, papan jari, senar dan beberapa macam perangkat pembantu. Perangkat pembantu tersebut antara lain pasak penyetel untuk setiap senar, ekor biola untuk menahan senar, pin dan tali untuk menahan ekor biola dan sebuah penyangga dagu. Biola berdasarkan jenis ukurannya adalah: 1/16, 1/10, 1/8, 1/4, 2/4 (1/2), 3/4 dan ukuran biola untuk dewasa adalah $4 / 4$.

Metode Suzuki adalah metode pengajaran paling luas yang diterapkan dalam permainan biola, meskipun juga bisa diterapkan pada alat-alat musik yang lain 
seperti cello, flute dan piano (Suzuki, 2008: 4). Fungsi metode Suzuki selain menuntun anak usia dini dalam bermain biola adalah melatih dan meningkatkan kreativitas anak usia dini dalam bermusik. Menurut Dirgualam (dalam Oki, 2006: 11), bahwa pada pembelajaran biola murid harus melakukan kegiatan mengamati, membaca notasi, menirukan, mencoba, dan melatih teknik yang diberikan oleh guru. Berdasarkan teori tersebut, belajar biola dapat berfungsi sebagai faktor pendorong anak untuk melatih kreativitas dalam bermusik.

Metode Suzuki juga memiliki keunggulan. Menurut Sinichi (2007: 15) pada buku Suzuki Method Book 1 dicantumkan bahwa kemudahan dalam metode tersebut antara lain: (1) Melodi yang digunakan mudah diingat, (2) Melampirkan organologi biola secara detail disertai penomoran pada setiap bagian biola dan notasinya, (3) Latihan yang ada dalam buku mempunyai tingkat kesulitan yang berbeda serta meningkat secara bertahap, (4) Method ini dilengkapi dengan CD audio yang dapat digunakan sebagai acuan sebelum memulai latihan. Dengan adanya kemudahan tersebut dan didukung kapasitas guru All Mozart yang memadai, dapat menjadikan faktor daya tarik anak usia dini untuk belajar biola dengan menyenangkan tanpa menemui kesulitan.

Anak usia dini adalah kelompok anak yang berada dalam proses pertumbuhan dan perkembangan yang bersifat unik. Mereka memiliki pola pertumbuhan dan perkembangan khusus sesuai dengan tingkat pertumbuhan dan perkembangannya. Anak usia dini masih berorintasi pada dirinya sendiri, minatnya lebih terarah pada dirinya sendiri dan jarang melakukan aktivitas bersama. Anak masih belajar mengendalikan aktivitas anggota tubuhnya, seperti berdiri dan berjalan. Dalam periode ini anak lebih diarahkan pada upaya mendukung kebebasan melakukan aktivitas fisik dan meningkatan kesadaran bagian tubuh (Mansur 2005: 88).
Usia anak berdasarkan pertumbuhan dan perkembangannya menurut Kartono (1979: 70) dibagi menjadi 5, yaitu: (1) 0 2 tahun adalah masa bayi, (2) $1-5$ tahun adalah masa kanak-kanak, (3) 6 - 12 tahun adalah masa anak-anak sekolah dasar, (4) 12 - 14 adalah masa remaja dan (5) $14-17$ tahun adalah masa pubertas awal.

Anak akan mengalami perkembangan fisik atau motorik yang akan mempengaruhi kehidupan anak, baik secara langsung ataupun tidak langsung (Hurlock, 1978: 114). Ciri perkembangannya ditandai dengan perkembangan badan, otot kasar dan otot halus, yang selanjutnya lebih disebut dengan motorik kasar dan motorik halus (Slamet Suyanto, 2005: 49). Perkembangan motorik kasar berhubungan dengan gerakan dasar yang terkoordinasi dengan otak seperti berlari, berjalan, melompat, memukul dan menarik. Sedangkan motorik halus berfungsi untuk melakukan gerakan yang lebih spesifik seperti menulis, melipat, menggunting dan lain-lain.

Ciri perkembangan anak yang lain adalah perkembangan bahasa. Berikut menurut Caroll Seefelt dan Barbara A.Wasik (2008: 74) tentang perkembangan bahasa anak usia dini adalah sebagai berikut: 1) Menguasai 4.000 - 6.000 kata, 2) Mampu berbicara dalam kalimat 5-6 kata, 3) Dapat berrpartisipasi dalam percakapan, sudah mampu mendengarkan orang lain berbicara dan menanggapinya, 4) Dapat belajar tentang kata mana yang diterima secara sosial dan mana yang tidak, 5) Perbendaharaan kosakata mencapai 5000 - 8.000 kata, 6) Stuktur kalimat menjadi lebih rumit, 7) Berbicara dengan lancar, benar dan jelas tata bahasa kecuali pada beberapa kesalahan pelafalan, 8) Dapat menggunakan kata ganti orang dengan benar, 9) Mampu mendengarkan orang yang sedang berbicara, 10) Senang menggunakan bahasa untuk permainan dan cerita.

Ciri perkembangan anak usia dini yang terakhir adalah berkembangnya musikal yang dialami dari proses belajar 
seiring berjalannya waktu. Pembelajaran musikal pada anak usia dini harus dikonsep agar anak merasa tidak terbebani dalam mencapai tugas perkembangannya. Suasana belajar perlu dibuat alami, hangat dan menyenangkan. Menurut Djohan (2009: 10) ada aktivitas yang umum dilakukan dalam pendidikan musik anak misalnya sebagai berikut: (1) Bernyanyi, (2) bermain musik, (3) Gerak ritmis dan (4) mendengarkan musik. Semua kegiatan tersebut memiliki manfaat kepada anak dalam hal artikulasi, membangun rasa percaya diri, melatih konsistensi dan melatih imajinasi anak.

\section{METODE}

Peneliti memilih All Mozart Music School sebagai lokasi penelitian karena dipandang sebagai tempat pembelajaran musik yang memiliki metode pembelajaran biola yang baik di Kota Kudus. Objek secara umum pada penelitian ini adalah murid biola di All Mozart Music School.

Teknik pengumpulan data ialah cara atau langkah yang digunakan peneliti untuk mendapatkan data yang diinginkan. Data yang dimaksud adalah data yang sesuai dengan apa yang terjadi di lapangan. Teknik pengumpulan data yang peneliti gunakan dalam melakukan penelitian ini adalah:

\section{Observasi}

Menurut Nawawi dan Martini (1995: 67) juga membagi teknik observasi menjadi dua macam: (1) Teknik observasi langsung, yaitu cara mengumpulkan data yang dilakukan melalui pengamatan dan pencatatan gejala-gejala (data) yang tampak pada obyek penelitian pada saat situasi sedang berlangsung, (2)Teknik observasi tidak langsung, cara mengumpulkan data yang dilakukan melalui pengamatan dan pencatatan gejala- gejala yang tampak pada obyek penelitian.
Faisal (dalam Sugiyono 2010: 64) mengklasifikasikan observasi menjadi observasi berpartisipasi (participant observation), observasi yang secara terangterangan dan tersamar (overt observation dan covert observation), dan observasi tak berstruktur (unstructured observation): (1) Observasi Partisipasif (2) Observasi

Terus Terang atau Tersamar. Peneliti melakukan pengumpulan data menyatakan terus terang kepada sumber data, bahwa ia sedang melakukan penelitian. Jadi mereka yang diteliti mengetahui sejak awal sampai akhir tentang aktivitas peneliti. (3)

Observasi Tak Berstruktur, Observasi dalam penelitian kualitatif dilakukan dengan tidak berstruktur, karena fokus penelitian belum jelas. Fokus observasi akan berkembang selama kegiatan observasi langsung. Observasi tak berstruktur adalah observasi yang tidak dipersiapkan secara sistematis tentang apa yang akan diobservasi.

Dalam melakukan observasi, peneliti terjun langsung ke lapangan untuk melihat dan meneliti fakta atau kenyataan apa saja yang terjadi, perilaku masyarakat ataupun pelakunya, kegiatan yang dilakukan, kemudian mendeskripsikannya. Berkaitan dengan permasalahan di penelitian ini, observasi dilakukan dengan melihat dan mengamati langsung proses pembelajaran biola di All Mozart Music School Kudus.

Wawancara

Penelitian ini dilakukan oleh peneliti dengan teknik wawancara terstruktur. Wawancara terstruktur menurut Guba dan Lincoln dalam Moleong (2007: 188) adalah wawancara yang pewawancaranya menetapkan sendiri masalah dan pertanyaan yang akan diajukan.

Untuk mengetahui lebih dalam mengenai berbagai informasi yang berhubungan dengan Pembelajaran biola di All Mozart Music School, penulis melakukan wawancara langsung dengan berbagai pihak, diantaranya kepada Abu Sofyan selaku pemilik All Mozart Music 
School. Wawancara yang peneliti lakukan khususnya tentang sejarah berdirinya All Mozart Music School, letak dan kondisi geografis All Mozart Music School, struktur organisasi All Mozart Music School dan pembelajaran biola dengan metode Suzuki di All Mozart Music School.

Studi dokumen

Teknik studi dokumen adalah cara pengumpulan data melalui peninggalan tertulis, seperti arsip-arsip dan termasuk buku-buku tentang pendapat, teori, dalil, atau hukum-hukum, dan lain-lain yang berhubungan dengan masalah penelitian (Margono 2003: 181). Salah satu bahan tertulis yang dijadikan sumber untuk menghimpun informasi oleh penulis adalah buku berjudul Suzuki Violin School Volume 1.

Guna memperoleh data yang relevan penulis mengumpulkan dan mengkaji setiap buku sebagai data dari buku-buku hasil penelitian. Buku yang dikaji tentang mengenai pembelajaran biola, foto-foto yang berkaitan, video pembelajaran biola yang tentunya proses pembelajaran pada metode Suzuki.

Dalam teknik pengumpulan data, triangulasi diartikan sebagai teknik pengumpulan data yang bersifat menggabungkan teknik pengumpulan data dan sumber data yang telah ada. Pengumpulan data dengan triangulasi, berarti peneliti mengumpulkan data yang sekaligus menguji kreibilitas data, yaitu mengecek kredibilitas data dengan berbagai teknik pengumpulan data dan berbagai sumber data, Sugiyono (2013: 241).

Bogdan dalam Sugiyono (2013: 244) menyatakan bahwa analisis data adalah proses mencari dan menyusun secara sistematis data yang diperoleh dari hasil wawancara, catatan lapangan, dan bahanbahan lain, sehingga dapat dengan mudah dipahami, dan temuannya dapat diinformasikan kepada orang lain. Berdasarkan hal di atas, dapat disimpulkan, bahwa analisis data adalah proses sistematis dalam mencari dan menyusun data yang diperoleh dari hasil observasi (catatan lapangan), wawancara, dan studi dokumen dengan memilah, menjabarkan, mengelompokkan dan membuat kesimpulan sehingga dapat lebih mudah dipahami untuk selanjutnya dapat dikembangkan dan dapat dievaluasi atau bahkan menjadi teori.

\section{Analisis Data}

Menurut Miles dan Huberman dalam Sugiyono (2013: 246) aktivitas dalam analisis data diataranya data reduction, data display, dan conclusion drawing/ verivication.

Data reduction disebut juga dengan reduksi data adalah merangkum, memilih hal yang pokok atau penting, membuat kategori dan membuang data yang tidak dipakai.. Data display atau penyajian data adalah men-display atau menyuguhkan data. Penyajian data dapat dilakukan dengan tabel, grafik, pictogram, uraian singkat, atau sejenisnya. Conclusion Drawing atau disebut juga dengan verifikasi atau penarikan kesimpulan. Kesimpulan yang dimaksud dalam penelitian kualitatif adalah kesimpulan yang baru dan belum pernah ada.

\section{HASIL DAN PEMBAHASAN}

Gambaran Umum dan Letak Kondisi Geografis All Mozart Music School Kudus

All Mozart Music School didirikan pada tahun 2011 oleh bapak H Ali Imran, beralamat lengkap di Jl.H.M Basuno No.99 (Eks Bioskop Ploso), Desa Ploso Rt. 02/01 Kecamatan Jati Kota Kudus. Kantor All Mozart Music School terbagi menjadi 2 bentuk bangunan yang berbeda. Bangunan pertama berbentuk seperti rumah seperti perumahan moderen pada umumnya. Bangunan ini berbahan tembok dan berfungsi sebagai kantor administrasi. Bangunan kedua berbentuk joglo atau rumah khas daerah Provinsi Jawa Tengah 
Jumlah pengurus All Mozart Music School terdiri dari Bapak Ali Imron selaku direktur utama, lalu direktur operasional dipegang oleh Abu Sofyan, M.Pd sebagai koordinator pengajar. Jumlah pengajar di All Mozart Music School sebanyak 16 orang. Jenis kursus musik yang ada di All Mozart Music School yaitu: (1) Kursus Piano, (2) Gitar Klasik, (3) Gitar Elektrik, (4) Drum, (5) Keyboard, (6) Vocal, (7) Biola. Proses belajar mengajar di All Mozart Music School dalam 1 bulan ada 4 kali pertemuan dengan durasi 30 menit.

Tujuan pembelajaran biola di All Mozart Music School

Tujuan pembelajaran biola di All Mozart Music School adalah: (1) Membangun kepercayaan diri anak dalam bermusik dengan cara menerapkan pembelajaran yang bernuansa ceria (2) Membangun kepercayaan diri murid yang bertujuan untuk melatih mental serta keberanian murid (3) Memberi pengarahan kepada murid tentang cara bermusik yang benar. Materi yang diajarkan adalah lagulagu yang ada di buku Suzuki yang berjudul Violin part 1.

Proses pelaksanaan pembelajaran biola dengan Metode Suzuki pada anak usia dini di All Mozart Music School Kudus terdapat beberapa tahap, yaitu : (1) Kegiatan awal pembelajaran yang dilakukan seluruh guru termasuk guru biola di All Mozart Music School adalah mengucapkan salam. Kegiatan Awal Murid Baru diawali dengan mendengarkan pertanyaan yang diajukan guru. Contoh pertanyaan dari guru berupa: "apakah sebelumnya pernah belajar musik"? Kegiatan Awal Murid Lama adalah menanyakan tugas pada pertemuan sebelumnya. Durasi waktu pada kegiatan awal berlangsung selama 10 menit.

Isi dari proses kegiatan inti di All Mozart Music School adalah guru memberikan gambaran umum mengenai materi yang akan dipelajari pada pertemuan tersebut, dan kegiatan inti berlangsung selama 15 menit. Guru menggunakan metode ceramah dan mulai menjelaskan dengan cara berbicara yang bertempo pelan mengenai materi yang akan dipelajari. Tahap kegiatan inti yang dialami anak usia dini pada saat pembelajaran biola, antara yang murid yang lama belajar dan baru belajar tentunya berbeda. Berdasarkan apa yang diperoleh pada waktu penelitian, peneliti menjabarkan kegiatan inti tersebut dengan membagi menjadi dua sebagai berikut.

Kegiatan Inti Murid Baru adalah: (1) Guru menuliskan judul materi yang ditulis di papan tulis, selanjutnya guru menjelaskan materi yang ditulis tersebut dengan menggunakan metode ceramah. (2) memperkenalkan alat musik biola baik secara organologinya maupun cara menggunakannya. (3) Langkah ketiga pada bagian inti ini adalah guru memberi kesempatan kepada setiap murid untuk menanyakan apa saja tentang alat biola.

Kegiatan Inti Murid Lama adalah menerapkan untuk melatih pendengaran anak usia dini sebelum mempelajari lagu. Lagu-lagu yang didengarkan dan diamati terdiri dari 2 lagu, yaitu: Lagu Twinkle Twinkle Litle Star dan lagu Lighty Row diamati secara seksama dengan menggunakan media laptop. Guru dengan aktif memandu anak dengan menyimak lagu per-bagian. Lagu yang dipelajari pada setiap pertemuannya adalah satu lagu. Hal ini dilanjutkan murid dengan menirukan permainan yang sudah dicontohkan oleh guru.

Kegiatan akhir yang dilakukan guru terhadap murid baru adalah melakukan pengulasan materi yang telah disampaikan guru. Kegiatan akhir murid lama adalah melakukan refleksi mengenai hasil yang diperoleh dan ditanamkan dari kegiatan pembelajaran. Guru melakukan penilaian lisan terhadap hasil pembelajaran murid usia dini.

Tahap pembelajaran biola di All Mozart Music School adalah pengenalan pada bagian-bagian biola. Setelah guru menjelaskan tentang bagian-bagian biola, 
guru menekankan pembelajaran untuk bagian-bagian yang dianggap paling penting untuk diketahui oleh murid yaitu : Senar (String), Jembatan (Bridge), Chinrest, Bow. Proses pengenalan biola yang telah dijelaskan guru harus disampaikan berulang-ulang agar anak cepat mengenal bagian tersebut.

Latihan awal yang dilakukan oleh guru terkait dengan penjelasan bagianbagian biola adalah dengan cara menggunakan pena terlebih dahulu. Pena tersebut dipegang dengan cara menempatkan ibu jari kurang lebih di posisi berlawanan dengan jari tengah dan jari manis, diusahakan jari harus membuat lingkaran. Tahap berikutnya adalah penempatan sikap berdiri ketika memegang biola. Guru memulai memandu murid dengan cara mencontohkan posisi letak kaki supaya membentuk huruf L. Setelah itu guru menata bagian kepala murid untuk membantu menyangga biola dengan dagu. Guru menambahkan agar bow selalu sejajar dengan jembatan biola (Bridge). Seluruh proses di atas tentunya disesuaikan dengan kemampuan murid.

Posisi berdiri yang baik adalah: (1) Guru memberi contoh dan mengajak murid untuk memposisikan tubuh dengan tegap dengan dada sedikit dibusungkan atau tidak bungkuk. (2) Guru mengajak murid untuk meletakkan biola di atas bahu dan meluruskan posisi kepala dengan pandangan tetap lurus kedepan. (3) Guru mengajak murid untuk mengarahkan kepala murid dengan hidung menghadap kepala biola dan letakkan dagu di atas chinrest

Pada latihan menggesek senar pada murid usia dini di All Mozart Music School adalah: (1) Guru mengajak murid untuk menempatkan sisi datar rambut busur di pertengahan antara bridge dengan papan jari, sehingga rambut busur melintasi perut (badan depan) biola. (2) Guru mencontohkan dalam menarik busur dan mulai menggesek senar paling bawah dan memotivasi murid untuk berusaha hingga biola mengeluarkan suara.
Proses Latihan Ritme dan membaca notasi adalah: Anak dapat meniru pola ketukan dengan menirukan cara bertepuk tangan kemudian menghentakkan kaki, Anak bertepuk tangan bersama-sama dengan pola ketukan yang dihasilkan dapat divariasikan untuk mengikutsertakan penekanan, Tambahan dua pola secara bersamaan. Pola pertama diberikan, kemudian anak mengikuti. Pola kedua di berikan contoh dan anak meniru pola pertama diikuti dengan pola kedua, Gerak dan lagu adalah gerakan yang dilakukan anak berdasarkan syair lagu yang biasanya dinyanyikan oleh anak secara bersamasama. Tujuan dari proses latihan ritme selain untuk melatih fisik anak juga agar anak mampu meniru secara tepat ketukan yang diperdengarkan, serta mengembangkan kemampuan mendengar yang lebih baik untuk mengembangkan pendengaran anak.

Proses pembelajaran notasi bertujuan: (1) Mengenalkan sight reading sejak dini pada murid, (2) Memberikan pengenalan tempo yang teratur. Metode yang digunakan dalam pembelajaran biola di All Mozart Music School adalah menggunakan Metode Suzuki yang diajarkan dengan beberapa metode pembelajaran gabungan atau kombinasi antara metode ceramah, metode demonstrasi, metode tanya jawab, metode latihan atau drill

Isi mengenai metode ceramah adalah tenang bagaimana menjelaskan beberapa hal yang berhubungan dengan pembelajaran biola, mulai dari nama bagian biola. Metode demonstrasinya adalah guru memainkan lagu Lighty Row, yang selanjutnya ditirukan murid dengan tempo dan dinamik yang benar dengan memberi keyakinan kepada murid untuk dapat menyelesaikan materi. Metode latihan atau drill bertujuan agar menanamkan materi kepada murid. Materi yang diajarkan oleh guru sebagai contoh adalah lagu Lighty Row. Materi tersebut dimainkan berulangulang untuk diperdengarkan terus menerus agar anak cepat hafal. Metode tanya jawab dalam pembelajaran biola dengan metode 
Suzuki di All Mozart Music School dilakukan setelah guru selesai menerangkan tentang notasi dan ritme. Guru memberikan kebebasan kepada murid untuk bertanya tentang seluruh proses pembelajaran atau materi yang telah diberikan

Bahan yang digunakan pada saat evaluasi di All Mozart Music School antara lain: 1. Pengetahuan tentang Alat Musik Biola 2. Posisi Penempatan Biola 3.Teknik Gesekan, 4.Ketukan/ Penjelasan lagu, 5. Penjarian Faktor-faktor yang Mempengaruhi dalam Keberhasilan Pembelajaran Alat Musik Biola di All Mozart Music School: Guru biola, orang tua murid, sarana prasarana. Faktor Penghambatnya adalah pelatih, murid, faktor Orang Tua

\section{PENUTUP}

Simpulan dari penelitian ini adalah : (1) Metode pembelajaran yang digunakan oleh pengajar untuk mengajar biola adalah Metode Suzuki. Metode Suzuki di All Mozart Music School mengutamakan (a) Penguasaan posisi berdiri pada saat memegang biola, (b) Penguasaan sikap memegang Bow dan (c) Penguasaan tata cara memegang senar. Metode pembelajaran yang digunakan adalah: (1) Metode ceramah, (2) Metode imitasi dan (3) Metode Demonstrasi, disamping itu dilengkapi dengan metode tanya jawab, pemberian tugas, dan metode latihan.

Saran peneliti: (1) Bagi Murid, murid seharusnya lebih bisa berkonsentrasi saat pembelajaran.. (2) Bagi pengajar, perlu memperbaiki cara penyampaian materi supaya lebih jelas dan dimengerti oleh muridnya. (3) Bagi All Mozart Music School hendaknya membuat kelas khusus biola yang lebih luas sehingga saat dibutuhkan untuk pembelajaran atau berlatih secara kelompok bisa sesuai dengan kapasitas yang dibutuhkan (4) Metode pembelajaran khususnya biola juga lebih difokuskan kepada masing-masing murid dengan bakat yang berbeda dapat lebih mudah untuk mengikuti materi-materi yang disampaikan.

\section{REFERENCES}

Ahmadi, Abu. 1998. Psikologi Umum. Yogyakarta: Rineka Cipta.

Arikunto, Suharsini. 1999. Prosedur Penilaian Suatu Pendekatan Praktik. Jakarta: Rineka Cipta

Banoe, Pono. 1992. Kamus Musik. Yogyakarta: Kanisius

Banoe, Pono. 2003. Kamus Musik. Kudus: Kanisius.

Burhan, Bungin. 2006. Metode Kualitatif. Jakarta: Kencana Pradana Media Group

Depdikbud. 1990. Kamus Besar Bahasa Indonesia. Jakarta: Balai Pustaka

Djohan. 2006. Terapi Musik. Yogyakarta: Galang Press.

Hamalik, Oemar. 1994. Kurikulum dan Pembelajaran. Jakarta: Bumi Aksara.

Jamalus. 1981. MUSIK 4. Jakarta: Titik Terang.

Harmono Sejati, I. (2013). BIOLA DALAM SENI PERTUNJUKAN GANDRUNG BANYUWANGI. Harmonia: Journal Of Arts Research And Education, 12(2). doi:http://dx.doi.org/10.15294/harmonia.v1 $2 \mathrm{i} 2.2517$

\section{Melalui Pengalaman Musik. Jakarta:} Depdikbud.

Laquais, Michael. 2011. Buku Pegangan Biola Grade I Rhythm Star Music School. Yogyakarta: Rhythm Star Music Press. 
Margono, S. 2003. Metodologi Penelitian Pendidikan. Jakarta: Rineka Cipta

Mathews, Max Wade and Wendy Thompson. 2011. The Enclyclopedia Of Music Instruments Of The Orchestra And The Great Composer. London: Hermes House.

Mukmin, N. 2004. Desain Pembelajaran. Kudus: Program Pasca Sarjana (UNY)

Roestijah, N. K. 1982. Masalah Masalah Ilmu Keguruan. Jakarta: PT Bina Aksara

Sadie, Stanley. 2011. The New Groove Dictionary of Music And Musician. London: Macmillan Publisher

Sadirman, A. M, 1986. Interaksi dan Motivasi Belajar Mengajar, Jakarta: Rajawali Press

Sagala, Syaiful. 2005. Konsep Dan Makna Pembelajaran. Bandung : Alfabeta

Sanjaya, Wina. 2008. Strategi Pembelajaran Berorientasi Standar Proses Pendidikan. Jakarta: Kencana Prenada Media grup

Syah, Muhibbin. 1995. Psikologi Pendidikan Suatu Pendekatan Baru. Bandung: Remaja Rosdakarya

Suharto, S. (2011). PENGEMBANGAN MATERI DAN KEGIATAN PEMBELAJARANNYA DALAM KURIKULUM TINGKAT SATUAN PENDIDIKAN BIDANG SENI MUSIK. Harmonia: Journal Of Arts Research And Education, $8(3)$. doi:http://dx.doi.org/10.15294/harmonia.v8 i3.780

Suryosubroto. B. 1997. Proses Belajar Mengajar disekolah. Jakarta: Rineka Cipta

Suharto, S. (2013). PROBLEMATIKA PELAKSANAAN PENDIDIKAN SENI MUSIK DI SEKOLAH KEJURUAN NON
SENI. Harmonia: Journal Of Arts Research And Education, 12(1). doi:http://dx.doi.org/10.15294/harmonia.v1 2i1.2221

Sumaryanto, F. (2011). EFEKTIFITAS PENGGUNAAN METODE SOLFEGIO UNTUK PEMBELAJARAN KETERAMPILAN BERMAIN MUSIK DI SEKOLAH DASAR (THE EFEKTIVITY OF USE OF SOLFIGIO METHOD TO TEACHING OF MUSIC SKILL IN ELEMENTARY). Harmonia: Journal Of Arts Research And Education, 6(2). doi:http://dx.doi.org/10.15294/harmonia.v6 i2.723

Kusumadewi, L., \& Suharto, S. (2011). PENINGKATAN HASIL BELAJAR SENI MUSIK DENGAN MEDIA AUDIO VISUAL MELALUI METODE BERVARIASI. Harmonia: Journal Of Arts Research And Education, 10(2). doi:http://dx.doi.org/10.15294/harmonia.v1 $0 \mathrm{i} 2.63$

Martopo, H. (2011). MUSIK SEBAGAI FAKTOR PENTING DALAM PENERAPAN METODE PEMBELAJARAN QUANTUM (MUSIC AS IMPORTANT FACTOR IN APPLICATION QUANTUM LEARNING METHOD). Harmonia: Journal Of Arts Research And Education, 6(2). doi:http://dx.doi.org/10.15294/harmonia.v6 i2.681

1997. Metode Pengajaran di Sekolah dan Pendekatan Baru Dalam Proses Belajar Mengajar, Kudus: Amarta.

Suzuki, Shinichi. 1978. Suzuki Violin Volume I. Florida: Summy Birchard.TIM MKDK, IKIP Semarang, 1996. Belajar dan Pembelajaran. Depdikbud, IKIP Semarang. 
Tirtaraharja, Umar. 1990. Pengertian

Pendidikan, Jakarta: Departemen

Pendidikan dan Kebudayaan.

Utuh (1987: 9) Pembelajaran Utuh, Harun, 1987. Proses Belajar Mengajar. Surabaya: Usaha Nasional.

Winkel. W.S. 1989. Psikologi Pendidikan, Jakarta: PT Gramedia 